REVIEW

Minimally invasive surgery

B Jaffray

Arch Dis Child 2005;90:537-542. doi: 10.1136/adc.2004.062760

In 1987 Mouret performed the first laparoscopic cholecystectomy, starting a revolution in surgery. For paediatricians it is difficult to appreciate the magnitude of what has occurred in this short period. The development of minimal access techniques represents the most significant change in surgical practice since the introduction of aseptic technique or safe anaesthesia. As with many innovations, rapid change, technical language, and the evangelism of pioneers has left confusion in its wake.

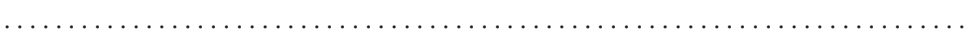

$\mathrm{T}$ his review is intended to allow paediatricians to understand the advantages of minimally invasive techniques in general, and suggest the place of specific procedures which are advocated for childhood disease, focusing on their application in abdominal and thoracic surgery.

\section{WHAT IS MINIMALLY INVASIVE SURGERY?}

Minimal access techniques seek to perform surgical procedures while avoiding the morbidity of conventional surgical wounds. This became possible through the combination of three technological advances: the Hopkins rod lens system and miniaturisation of video cameras allow the surgeon's visualisation inside the body at least equal to open surgery, while standing in a normal posture. Insufflation devices allow controlled distension of body cavities with gas to provide the surgeon space to work.

\section{Advantages of minimally invasive techniques}

There are three principal advantages. Firstly, avoidance of large wounds should lead to less postoperative pain; this should in turn minimise the morbidity due to immobility such as postoperative atelectasis and venous thrombosis. ${ }^{1}$ Secondly, avoidance of a wound should lead to earlier hospital discharge and shorter convalescence. Thirdly, the small portholes of laparoscopic surgery should lead to improved cosmesis. With the exception of cosmesis (which paradoxically is frequently the most important advantage in patient's perceptions!), these are usually the indices by which minimal access surgery is compared to open surgery. Although it may seem obvious that smaller incisions should result in less pain and quicker recovery, in well designed trials the advantages of minimally invasive techniques can be surprisingly difficult to demonstrate. ${ }^{2}$ There are a number of other possible advantages claimed for minimal access such as better visualisation of inaccessible areas, minimisation of risk of adhesive intestinal obstruction, and a decreased inflammatory response.

\section{Disadvantages of minimally invasive techniques}

Chief among the disadvantages is the "learning curve" of the new techniques. Complications usually occur early in the surgeon's overall experience of minimal access, or when an experienced surgeon is expanding into new procedures. ${ }^{3}$ Recognition of this has led to a proliferation of training courses, simulators, web based videos, and mentoring systems. It should also be acknowledged that open surgery too has a learning curve, and it is inevitable that surgical training carries some morbidity. Parents, and paediatricians considering referring their patients, may well ask: "how long is the surgeon's learning curve?". Using fundoplication as a guide, one study specified the first 20 procedures as the period of maximum risk. ${ }^{4}$

The creation of a gas filled cavity also carries risks. Inadvertent perforation of viscera during the initial puncture, haemodynamic and ventilatory changes, and gas embolus are all recognised. In addition there are procedure specific risks created by the use of minimally invasive techniques such as port site metastasis following laparoscopic cancer surgery, and port site hernia and haemorrhage following any type of surgery.

Minimal access procedures usually take longer than conventional open surgery, with consequent reduced throughput; the implications of this may be unwelcome to those responsible for management of healthcare systems. This may be offset by reduced costs from earlier hospital discharge.

\section{WHAT IS THE PLACE OF MINIMALLY INVASIVE SURGERY IN PAEDIATRICS?}

This subject is rapidly changing, and the only certainty is that minimal access techniques will be increasingly applied to children. At present paediatricians may be faced with a dilemma: are the advantages of such techniques so great that children should be referred to surgeons offering minimal access, or is conventional open surgery still appropriate? While the best comparisons of open and minimal access techniques have been performed in adults, there are often difficulties in applying the conclusions of such studies to children. For example, most paediatric surgeons would aim to achieve appendicectomy or excision of a multi-cystic dysplastic kidney through very small incisions, which might offer identical recovery to a minimal access approach. Considerations about early return to wage earning 
activity will influence adult patients' preferences, but are irrelevant to a baby undergoing pyloromyotomy.

Upper gastrointestinal surgery Gastro-oesophageal reflux (table 1)

Despite fundoplication being the commonest major procedure performed by paediatric surgeons, there are only preliminary reports of one randomised comparison. Fundoplication fulfils many of the pre-requisites for a procedure to be successfully translated from open to minimal access in that the conventional procedure produces a large painful wound and significant hospital stay while there are no technical difficulties in the formation of a gastric wrap with laparoscopic instrumentation.

There are eight randomised trials comparing open with laparoscopic fundoplication using adult patients. With the exception of the study of Bais and colleagues, ${ }^{5}$ where patients undergoing laparoscopic fundoplication experienced dysphagia, there is no difference in controlling reflux, while laparoscopy offers reduced pain and earlier discharge. I believe that children should be offered laparoscopic fundoplication.

\section{Oesophageal atresia}

Conventional repair of oesophageal atresia in the newborn produces survival in more that $95 \%$ of cases, with excellent long term function in the majority. Thoracoscopic repair will not lead to improved survival since mortality is largely because of concomitant uncorrectable congenital heart disease, while construction of a less than perfect anastamosis may very well compromise long term function. Any suggestion of excess morbidity as a result of thoracoscopic techniques should be a cause for concern. Conventional surgery will remain the norm for the foreseeable future.

\section{Achalasia (table 2)}

Surgical treatment of achalasia consists of a vertical myotomy at the site of the lower oesophageal sphincter (Heller's operation), coupled with some form of fundoplication. Two controlled studies of open versus laparoscopic approaches have been reported in adults, both of which suggest advantages to the use of laparoscopy. Paediatric case series do not suggest any difficulties in applying the procedure to children. ${ }^{6}$ A recent review suggests that surgical myotomy is the treatment of choice. ${ }^{7}$ When the decision is to operate, children with achalasia should be offered a laparoscopic myotomy and anti-reflux procedure.

\section{Idiopathic infantile pyloric stenosis (table 2)}

In one prospective randomised comparison of laparoscopic and open pyloromyotomy; ${ }^{8}$ babies were shown to feed significantly earlier and vomit significantly less after laparoscopic pyloromyotomy. In seven comparative studies, one reported an unacceptable incidence of complications following laparoscopic pyloromyotomy, ${ }^{9}$ although this did not prevent the authors persisting in their recommendation of the procedure! Three reported no difference. Incomplete pyloromyotomy is a rare event following conventional pyloromyotomy, but is reported more often after laparoscopic surgery. ${ }^{10}$ Discharge from hospital after conventional pyloromyotomy is typically less than 48 hours, while the use of the circumbilical incision leads to a cosmetically pleasing scar, largely negating the advantages of minimal access techniques. Laparoscopic pyloromyotomy is acceptable, but advantages over conventional surgery may be minimal.

\section{Hepato-biliary surgery}

\section{Cholelithiasis (table 1)}

Cholecystectomy is the most frequently performed laparoscopic procedure, although it is accepted that the incidence of

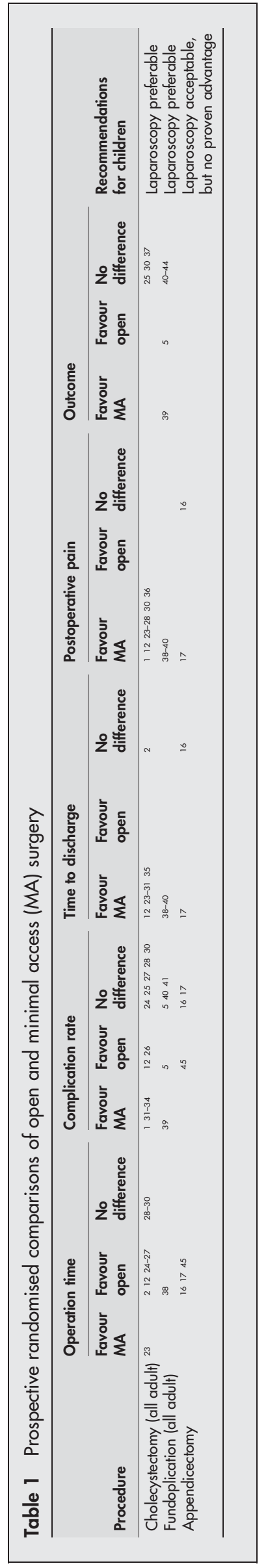


bile duct injury has increased as a result of the change from conventional surgery. This can be a life threatening event. ${ }^{11}$ There are no randomised controlled studies of laparoscopic and conventional cholecystectomy in children. The comparison is complicated since adult literature frequently compares laparoscopic to "mini-laparotomy" cholecystectomy, which is an open operation performed through a small incision, while children with gallstones will often require simultaneous splenectomy. While the advantages of laparoscopic cholecystectomy in adults may not be as great as initially hoped, ${ }^{12}$ the procedure is now accepted as the gold standard. Controversial issues include whether a cholangiogram is always indicated, as some suggest, ${ }^{3}$ even if the anatomy is clear and there are no other features to suggest ductal stones. Non-randomised paediatric studies do not suggest any difficulties specific to children, ${ }^{13}$ and therefore children should preferentially receive laparoscopic cholecystectomy.

\section{Choledochal cyst/biliary atresia}

Because of risks of infection, perforation, and malignancy, a choledochal cyst is treated by excision of the entire extrahepatic biliary tract and reconstruction with a loop of jejunum. Laparoscopic techniques are described, but there are unlikely ever to be controlled trials. Attempts at laparoscopic biliary reconstruction in children should be recognised as a major undertaking requiring advanced skills. Whereas the morbidity of a poorly formed, strictured biliary reconstruction can be lifelong with secondary biliary cirrhosis, the benefits of a laparoscopic rather than conventional approach to such a reconstruction are unlikely to be enjoyed by the child after a month has passed. Surgeons should be clear about the relative merits and risks of attempting such a procedure laparoscopically.

The dissection and reconstruction demanded by the anomaly of biliary atresia are similar, with the added imperative of the outcomes of surgery being heavily dependent on early diagnosis and intervention. The restrictions of space within the abdomen of a neonate make this author sceptical about the wisdom of attempting such a reconstruction laparoscopically.

\section{Spherocytosis/idiopathic thrombocytopenic purpura (table 2)}

Laparoscopic splenectomy offers worthwhile advantages over the open procedure, including reduced blood loss, ${ }^{14}$ and will frequently be combined with laparoscopic cholecystectomy in children. ${ }^{15}$ The control of the large vessels within the splenic pedicle may require either a mechanical stapler or a specialised haemostatic device. Children should be offered laparoscopic splenectomy.

\section{Colorectal surgery}

Paediatric colorectal surgery is principally concerned with the congenital anomalies of Hirschsprung's disease and imperforate anus, and the acquired conditions of inflammatory bowel disease and appendicitis, all subject to laparoscopic surgery.

\section{Appendicitis (table 1)}

There are two prospectively randomised trials of laparoscopic versus open appendicectomy in children, ${ }^{16}{ }^{17}$ one of which has been subject to further analysis of the subgroup of complicated appendicitis. The two trials came to opposite conclusions. In the study of Lintula et al, children undergoing laparoscopic appendicectomy for uncomplicated appendicitis experienced less postoperative pain and earlier hospital discharge. ${ }^{17}$ However, the mean advantage over the open procedure was $0.13 \mathrm{mg} / \mathrm{kg}$ less of oxycodone analgesia and discharge 0.7 days earlier, which seems of doubtful value. The same authors express concern about the use of laparoscopy in

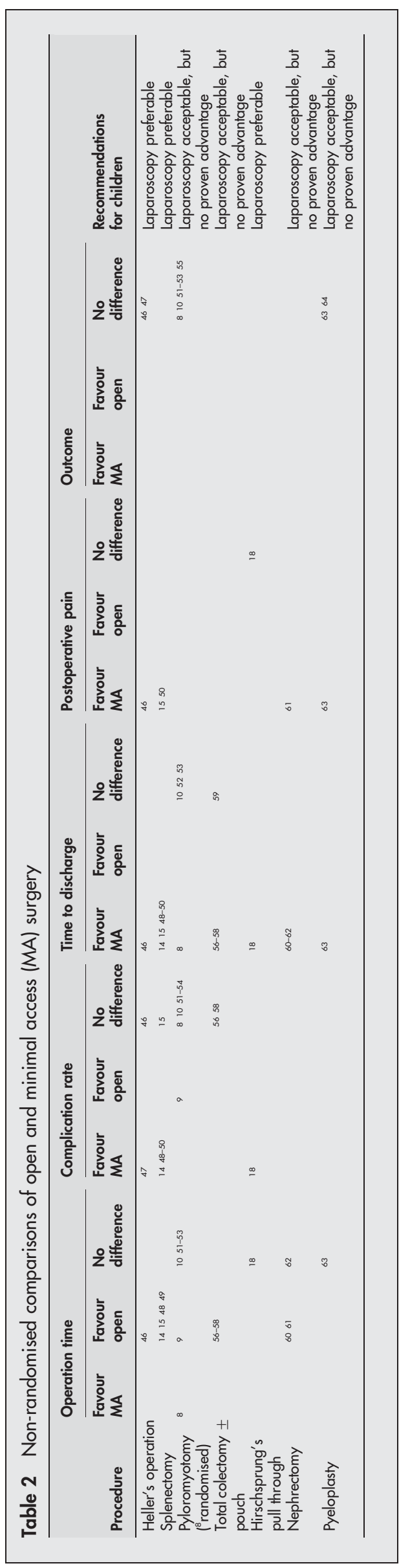


complex appendicitis, which leads to a higher incidence of residual intra-abdominal abscess. The benefits of the minimally invasive technique are probably real, but they are certainly not large enough to displace conventional open appendicectomy.

\section{Colectomy for acquired disease (table 2)}

Comparisons of open versus laparoscopic colectomies often study patients with colorectal carcinoma, and this offers little guidance to paediatricians whose concern is with benign disease. Excluding such studies, three non-randomised studies have been reported, with mixed results. There is no proven benefit to performing colonic resection laparoscopically in children.

\section{Colorectal surgery for congenital disease (table 2)}

There are several reports on laparoscopic assisted techniques in the treatment of both Hirschsprung's disease and anorectal malformations, including one non-randomised comparison of open and laparoscopic pull through for Hirschsprung's disease. ${ }^{18}$ Unfortunately this study was compromised by utilising infants of around $1 \frac{1}{2}$ years of age, most of whom had received a prior colostomy, whereas most would favour definitive surgery without a colostomy in the first few weeks of life. Because of the infrequency of these conditions, it is unlikely that a randomised trial will ever be performed to prove the benefits of minimal access. In these circumstances, providing comparison with historical controls does not reveal excess morbidity among laparoscopically treated infants, minimal access is appropriate, but not mandatory. The ACE procedure for salvage of impaired faecal continence particularly lends itself to laparoscopic techniques if and when the appendix is going to be used as the nonrefluxing catheterisable channel.

\section{Paediatric urology}

Historically the first area where laparoscopy was adopted outside gynaecology was in the evaluation of impalpable testes by paediatric surgeons, and this remains a common indication. Minimal access has been extended from purely diagnostic to therapeutic use with the ability to perform testicular mobilisation laparoscopically. In the same anatomical area, laparoscopic clipping of the testicular pedicle is effective treatment for a varicocele. One area where laparoscopy is clearly advantageous is in the harvesting of kidneys for transplantation from living related donors.

\section{Renal dysplasia (table 2)}

Total or partial nephrectomy performed laparoscopically for benign disease in children is described, and controlled comparisons in adult patients suggest that there are advantages. However, multi-cystic dysplastic kidneys are frequently less than $3 \mathrm{~cm}$ long and may be removed through very small incisions. For such kidneys, there may be no advantage to laproscopic nephrectomy. With this caveat, laparoscopic nephrectomy is appropriate in children.

\section{Pelvi-ureteric junction stenosis (table 2)}

Congenital obstruction of the ureter at it's junction with the renal pelvis leads to intermittent loin pain and can result in loss of renal function. Pyeloplasty relieves the obstruction either by re-anastamosing the ureter or by a localised plastic procedure. The procedure is increasingly performed laparoscopically in adult practice and is described in children, although technically demanding with a high conversion rate. ${ }^{19}$ There are no controlled studies in children, and while adult experience is encouraging, it should be remembered that the consequence of an inadequate pyeloplasty may be loss of the kidney.

\section{Vesico-ureteric reflux}

Although there are reports of laparoscopic reimplantation of ureter, these are small, uncontrolled descriptions, and even their authors seem unenthusiastic. However, the procedure should lend itself to a trans-vesical minimal access approach, and may well become accepted.

\section{Thoracic surgery}

Cystic adenomatoid malformation/congenital emphysema/bronchopulmonary sequestration These congenital pulmonary anomalies are frequently detected antenatally, and are controversial because of their uncertain natural history. In adults pulmonary lobectomy is increasingly performed thoracoscopically, taking advantage of mechanical staplers to both transect lung and major vascular pedicles. There are no surgical staplers applicable to neonatal or infant lung, and alternative means of sealing lung are used. Thoracotomy in young children can lead to chest deformity caused by rib fusion and disordered growth, and avoidance of this may be a specific advantage of thoracoscopy in infants. Currently, all that can be said is that while there is no proof of their superiority such procedures are technically feasible, even in infants as young as 3 months. ${ }^{20}$

\section{Endocrine surgery}

Both thyroidectomy and adrenalectomy may be performed using minimal access. There are few controlled comparisons in the adult literature and none for children. Given the rarity of these procedures in paediatric surgery it may be that minimal access approaches will be restricted to adult endocrine surgeons for the foreseeable future.

\section{Surgical oncology}

The principal solid tumours of childhood are best managed within protocols, which currently do not specify minimal access techniques. Consequently there have been few reports of the therapeutic use of these techniques in paediatric oncology. Minimal access techniques do have a clear role in the evaluation of suspicious intra-thoracic or intra-abdominal masses, particularly in the assessment of potential metastatic disease. Suspicious masses in children with known malignancy frequently proved innocent on biopsy material obtained with thoracoscopy or laparoscopy. ${ }^{21}$

\section{Surgery of the body wall and diaphragm} Inguinal hernia

Some paediatric surgeons advocate routinely exploring the contralateral groin when an inguinal hernia is repaired in a child. Because the incidence of asymptomatic occult hernia is low, this leads to a large number of unnecessary procedures. As a compromise, others have suggested that when a groin hernia is explored, a laparoscope can be inserted through the hernial sac to assess the contralateral inguinal ring. ${ }^{3}$ The author's view is that even this is probably unjustified since many apparently open inguinal rings will never result in a clinically important hernia.

It is also possible to repair children's groin hernia using an entirely laparoscopic approach. Given the minor nature of conventional herniotomy surgery it is difficult to see this offering any advantages to children.

\section{Diaphragmatic hernia}

There are several reports describing repair of either Bochdalek or Morgagni hernias either laparoscopically or thoracoscopically. Although the reduction and repair is straightforward in older children, whether minimal access offers survival advantages to a neonate born with a Bochdalek hernia and with significant pulmonary hypoplasia is unknown. Conventional repair leads to a reduction in pulmonary compliance, and perhaps there is a role for minimal surgery in this situation. 


\section{Pectus excavatum}

This congenital disorder of the chest leaves the child with a backward pointing sternum and an unattractive dip in the middle of their chest; there may be functional effects in later life with decreased exercise tolerance. Conventional correction involves a major resection and refashioning of several costal cartilages. A new minimal access technique, the Nuss procedure, has been developed which offers reconstruction with much less trauma to the thorax.

\section{Diagnostic uses of minimal access}

In a study of 15 children with recurrent abdominal pain, and uninformative imaging, laparoscopic examination was claimed to lead to positive diagnostic findings in 11 , and resolution of pain in all. ${ }^{22}$ Whether lymphoid hyperplasia of the appendix is a normal variant or a positive diagnostic finding is open to argument, but it is clear that this problematic group of children can be usefully assessed with laparoscopic techniques. Intra-thoracic pathology may be similarly assessed. ${ }^{3}$

\section{CONCLUSIONS}

Although there are many procedures where we can use minimal access, there are no procedures where we must use these techniques. In published paediatric experience there is not a single procedure where evidence proves the benefits of such surgery. Surgeons who hold that non-randomised comparisons with historical controls, or uncontrolled case series are sufficient, or that the benefits of minimal access techniques are so obvious as to not require proof of efficacy would be advised to study Majeed and colleagues. ${ }^{2}$ At present, the best we can say is that by interpolating the results of trials of open versus minimal access surgery performed in adults we hope the proven benefits exist also for children.

Where procedures have been first reported in adult series, there has usually been an initial excess morbidity. Forewarned of dangers, paediatric surgeons have been largely able to avoid the pitfalls which have been marked out by the surgeons who have gone before them. Paediatric surgeons need to be mindful that for conditions which are exclusively seen in children such as oesophageal or biliary atresia, this excess morbidity may very well fall on their patients.

As with trials and licensing of pharmaceuticals for children, compromises must be made in everyday paediatric practice when evaluating the use of minimal access techniques. The increasingly hostile regulatory environment towards the creation of prospective randomised research coupled with the virtual disappearance of university and government support for clinical research means that for many surgical procedures in children there will never be unequivocal evidence of the superiority of minimal access techniques over conventional surgery. Nevertheless it is reasonable to assume that minimal access offers reduced pain, earlier discharge, and better cosmesis for many procedures. Within the caveats expressed, these are real advantages which should not be denied to children undergoing surgery.

The next decade will see further technological advances with more procedures possible in children using minimal access. It is easy for surgeons to claim a "first" by performing such operations, but the publishing of small uncontrolled series fails to prove the superiority of the new over the old. What we need is proof of efficacy for new minimal access procedures and this can only come from randomised trials. This slow and difficult work, rather than the beguiling new technologies, should be the focus of effort for both paediatric surgeons and the paediatricians who refer us our patients.

Competing interests: none declared

\section{REFERENCES}

1 Karayiannakis AJ, Makri GG, Mantzioka A, et al. Postoperative pulmonary function after laparoscopic and open cholecystectomy. $\mathrm{Br} J$ Anaesth 1996;77:448-52

2 Majeed AW, Troy G, Nicholl JP, et al. Randomised, prospective, single-blind comparison of laparoscopic versus small-incision cholecystectomy. Lancet 1996;347:989-94.

3 Chen MK, Schropp KP, Lobe TE. Complications of minimal-access surgery in children. J Pediatr Surg 1996;31:1161-5.

4 Watson DI, Baigrie RJ, Jamieson GG. A learning curve for laparoscopic fundoplication. Ann Surg 1996;224:198-203.

5 Bais JE, Bartelsman JF, Bonjer HJ, et al. Laparoscopic or conventional Nissen fundoplication for gastro-oesophageal reflux disease: randomised clinical trial. The Netherlands Antireflux Surgery Study Group. Lancet 2000;355:170-4

6 Mattioli G, Esposito C, Pini Prato A, et al. Results of the laparoscopic HellerDor procedure for pediatric esophageal achalasia. Surg Endosc 2003; 17:1650-2.

7 Spiess $\mathrm{AE}$, Kahrilas PJ. Treating achalasia: from whalebone to laparoscope. JAMA 1998;280:638-42.

8 Fujimoto T, Lane GJ, Segawa O, et al. Laparoscopic extramucosal pyloromyotomy versus open pyloromyotomy for infantile hypertrophic pyloric stenosis: which is better? J Pediatr Surg 1999;34:370-2.

9 Sitsen E, Bax NM, van der Zee DC. Is laparoscopic pyloromyotomy superior to open surgery? Surg Endosc 1998;12:813-15.

10 Greason KL, Thompson WR, Downey EC, et al. Laparoscopic pyloromyotomy for infantile hypertrophic pyloric stenosis: report of 11 cases. J Pediatr Surg 1995;30:1571-4

11 Buell JF, Cronin DC, Funaki B, et al. Devastating and fatal complications associated with combined vascular and bile duct injuries during cholecystectomy. Arch Surg 2002;137:703-10.

12 Ros A, Gustafsson L, Krook H, et al. Laparoscopic cholecystectomy versus mini-laparotomy cholecystectomy: a prospective, randomized, single-blind study. Ann Surg 2001;234:741-9.

13 Kim PC, Wesson D, Superina R, et al. Laparoscopic cholecystectomy versus open cholecystectomy in children: which is better? J Pediatr Surg 1995;30:971-3.

14 Park A, Marcaccio M, Sternbach M, et al. Laparoscopic vs open splenectomy. Arch Surg 1999;134:1263-9.

15 Rescorla FJ, Breiffeld PP, West KW, et al. A case controlled comparison of open and laparoscopic splenectomy in children. Surgery 1998;124:670-6.

16 Little DC, Custer MD, May BH, et al. Laparoscopic appendectomy: an unnecessary and expensive procedure in children? J Pediatr Surg 2002;37:310-17.

17 Lintula H, Kokki H, Vanamo K. Single-blind randomized clinical trial of laparoscopic versus open appendicectomy in children. Br J Surg 2001;88:510-14.

18 Curran TJ, Raffensperger JG. Laparoscopic Swenson pull-through: a comparison with the open procedure. J Pediatr Surg 1996;31:1155-6.

19 El-Ghoneimi A, Farhat W, Bolduc S, et al. Laparoscopic dismembered pyeloplasty by a retroperitoneal approach in children. BJU Int 2003;92:104-8.

20 Albanese CT, Sydorak RM, Tsao K, et al. Thoracoscopic lobectomy for prenatally diagnosed lung lesions. J Pediatr Surg 2003;38:553-5.

21 Holcomb GW 3rd, Tomita SS, Haase GM, et al. inimally invasive surgery in children with cancer. Cancer 1995;76:121-8.

22 Stylianos S, Stein JE, Flanigan LM, et al. Laparoscopy for diagnosis and treatment of recurrent abdominal pain in children. $J$ Pediatr Surg 1996;31:1158-60.

23 Huang SM, Wu CW, Lui WY, et al. A prospective randomised study of laparoscopic $v$. open cholecystectomy in aged patients with cholecystolithiasis. S Afr J Surg 1996;34:177-9.

24 Trondsen E, Reiertsen O, Andersen OK, et al. Laparoscopic and open cholecystectomy. A prospective, randomized study. Eur J Surg 1993;159:217-21.

25 McMahon AJ, Russell IT, Baxter JN, et al. Laparoscopic versus minilaparotomy cholecystectomy: a randomised trial. Lancet 1994;343:135-8.

26 McGinn FP, Miles AJ, Uglow M, et al. Randomized trial of laparoscopic cholecystectomy and mini-cholecystectomy. Br J Surg 1995;82:1374-7.

27 Berggren U, Gordh T, Grama D, et al. Laparoscopic versus open cholecystectomy: hospitalization, sick leave, analgesia and trauma responses. Br J Surg 1994;81:1362-5.

28 Kunz R, Orth K, Vogel J, et al. Laparoscopic cholecystectomy versus mini-lapcholecystectomy. Results of a prospective, randomized study. Chirurg 1992;63:291-5.

29 Dionigi R, Dominioni L, Benevento A, et al. Effects of surgical trauma of laparoscopic vs. open cholecystectomy. Hepatogastroenterology 1994;41:471-6.

30 Hendolin HI, Paakonen ME, Alhava EM, et al. Laparoscopic or open cholecystectomy: a prospective randomised trial to compare postoperative pain, pulmonary function, and stress response. Eur J Surg 2000;166:394-9.

31 Kiviluoto T, Siren J, Luukkonen $\mathrm{P}$, et al. Randomised trial of laparoscopic versus open cholecystectomy for acute and gangrenous cholecystitis. Lancet 1998;351:321-5

32 Hasukic S, Mesic D, Dizdarevic E, et al. Pulmonary function after laparoscopic and open cholecystectomy. Surg Endosc 2002;16:163-5.

33 Coskun I, Hatipoglu AR, Topaloglu A, et al. Laparoscopic versus open cholecystectomy: effect on pulmonary function tests. Hepatogastroenterology 2000;47:341-2. 
34 Mimica Z, Biocic M, Bacic A, et al. Laparoscopic and laparotomic cholecystectomy: a randomized trial comparing postoperative respiratory function. Respiration 2000;67:153-8.

35 Barkun JS, Barkun AN, Sampalis JS, et al. Randomised controlled trial of laparoscopic versus mini cholecystectomy. The McGill Gallstone Treatment Group. Lancet 1992;340:1116-19.

36 Squirrell DM, Majeed AW, Troy G, et al. A randomized, prospective, blinded comparison of postoperative pain, metabolic response, and perceived health after laparoscopic and small incision cholecystectomy. Surgery 1998;123:485-95.

37 McMahon AJ, Ross S, Baxter JN, et al. Symptomatic outcome 1 year after laparoscopic and minilaparotomy cholecystectomy: a randomized trial. Br J Surg 1995;82:1378-82.

38 Nilsson G, Larsson S, Johnsson F. Randomized clinical trial of laparoscopic versus open fundoplication: blind evaluation of recovery and discharge period. Br J Surg 2000;87:873-8.

39 Chrysos E, Tsiaoussis J, Athanasakis E, et al. Laparoscopic vs open approach for Nissen fundoplication. A comparative study. Surg Endosc 1679;16:1679-84.

40 Ackroyd R, Watson DI, Majeed AW, et al. Randomized clinical trial of laparoscopic versus open fundoplication for gastro-oesophageal reflux disease. Br J Surg 2004;91:975-82.

41 Laine S, Rantala A, Gullichsen R, et al. Laparoscopic vs conventional Nissen fundoplication. A prospective randomized study. Surg Endosc 1997; 11:441-4.

42 Luostarinen M, Virtanen J, Koskinen M, et al. Dysphagia and oesophageal clearance after laparoscopic versus open Nissen fundoplication. A randomized, prospective trial. Scand J Gastroenterol 2001;36:565-71.

43 Wenner J, Nilsson G, Oberg S, et al. Short-term outcome after laparoscopic and open 360 degrees fundoplication. A prospective randomized trial. Surg Endosc 2001;15:1124-8.

44 Heikkinen TJ, Haukipuro K, Bringman S, et al. Comparison of laparoscopic and open Nissen fundoplication 2 years after operation. A prospective randomized trial. Surg Endosc 2000;14:1019-23.

45 Lintula H, Kokki H, Vanamo K, et al. Laparoscopy in children with complicated appendicitis. J Pediatr Surg 2002;37:1317-20.

46 Ancona $E$, Anselmino M, Zaninotto $G$, et al. Esophageal achalasia: laparoscopic versus conventional open Heller-Dor operation. Am J Surg 1995; 170:265-70

47 Collard JM, Romagnoli R, Lengele B, et al. Heller-Dor procedure for achalasia: from conventional to video-endoscopic surgery. Acta Chirurgica Belgica 1996;96:62-5.

48 Marassi A, Vignali A, Zuliani W, et al. Splenectomy for idiopathic thrombocytopenic purpura: comparison of laparoscopic and conventional surgery. Surg Endosc 1999;13:17-20.
49 Smith CD, Meyer TA, Goretsky MJ, et al. Laparoscopic splenectomy by the lateral approach: a safe and effective alternative to open splenectomy for hematologic diseases. Surgery 1996; 120:789-94.

50 Donini A, Baccarani U, Terrosu G, et al. Laparoscopic vs open splenectomy in the management of hematologic diseases. Surg Endosc 1999;13:1220-5.

51 Scorpio RJ, Tan HL, Hutson JM. Pyloromyotomy: comparison between laparoscopic and open surgical techniques. Journal of Laparoendoscopic Surgery 1995;5:81-4.

52 Campbell BT, McLean K, Barnhart DC, et al. A comparison of laparoscopic and open pyloromyotomy at a teaching hospital. J Pediatr Surg 2002;37:1068-71.

53 Caceres M, Liu D. Laparoscopic pyloromyotomy: redefining the advantages of a novel technique. Journal of the Society of Laparoendoscopic Surgeons 2003:7:123-7.

54 Yagmurlu A, Barnhart DC, Vernon A, et al. Comparison of the incidence of complications in open and laparoscopic pyloromyotomy: a concurrent single institution series. J Pediatr Surg 2004;39:292-6.

55 Bufo AJ, Merry C, Shah R, et al. Laparoscopic pyloromyotomy: a safer technique. Pediatr Surg Int 1998;13:240-2.

56 Marcello PW, Milsom JW, Wong SK, et al. Laparoscopic restorative proctocolectomy: case-matched comparative study with open restorative proctocolectomy. Dis Colon Rectum 2000;43:604-8.

57 Dunker MS, Bemelman WA, Slors JF, et al. Laparoscopic-assisted vs open colectomy for severe acute colitis in patients with inflammatory bowel disease (IBD): a retrospective study in 42 patients. Surg Endosc 2000; 14:911-14.

58 Chen HH, Wexner SD, Weiss EG, et al. Laparoscopic colectomy for benign colorectal disease is associated with a significant reduction in disability as compared with laparotomy. Surg Endosc 1998;12:1397-400.

59 Schmitt SL, Cohen SM, Wexner SD, et al. Does laparoscopic-assisted ileal pouch anal anastomosis reduce the length of hospitalization? Int J Colorectal Dis 1994;9:134-7.

60 Hamilton BD, Gatti JM, Cartwright PC, et al. Comparison of laparoscopic versus open nephrectomy in the pediatric population. J Urol 2000;163:937-9.

61 Robinson BC, Snow BW, Cartwright PC, et al. Comparison of laparoscopic versus open partial nephrectomy in a pediatric series. J Urol 2003;169:638-40

62 El-Ghoneimi A, Farhat W, Bolduc S, et al. Retroperitoneal laparoscopic vs open partial nephroureterectomy in children. BJU Int 2003;91:532-5.

63 Baldwin DD, Dunbar JA, Wells N, et al. Single-center comparison of laparoscopic pyeloplasty, Acucise endopyelotomy, and open pyeloplasty. $J$ Endourol 2003;17:155-60.

64 Baver JJ, Bishoff JT, Moore RG, et al. Laparoscopic versus open pyeloplasty: assessment of objective and subjective outcome. J Urol 1999; 162(3 pt 1):692-5. 